\title{
Application of Improved BP Neural Network in Hybrid Control Model of Lime Quality
}

\author{
Lingli Zhu ${ }^{1, a^{*}}$ and Tingzhong Wang ${ }^{1}$ \\ ${ }^{1}$ College of Information Technology, Luoyang Normal University, Luoyang, 471934, China \\ azhulinglils@163.com
}

Keywords: Improved Neural Network; Lime; Expert System; BP; Hybrid Control

\begin{abstract}
In this paper, a method of combining neural network with expert system is proposed, which can realize the control model of real time feedback and control parameters. The model is based on the parameters of production condition, and the current lime quality is predicted. Through the quality of lime and control parameters, using association rule base of expert system, reasoning that lime control parameter adjustment, timely feedback to the lime production control system, to achieve the purpose of real-time control of the quality of lime. The paper presents application of improved BP neural network in hybrid control model of lime quality.
\end{abstract}

\section{Introduction}

The production control process of the rotary kiln is the production of high quality lime under the premise of stable output. The automatic control system of lime rotary kiln can control the quality of the product by controlling the operation of the fuel quantity, air quantity, and equipment. However, the quality of lime can not be obtained in real time, and the production control system can not get the product quality information in time [1]. At present, the control system of lime rotary kiln is the main technology workers. Through the process system on-line monitoring state parameters to predict the current product quality, and it is as the basis for the adjustment of control parameters. The quality of products is greatly influenced by artificial judgment or off-line detection.

In this paper, the ability of the neural network is used to deal with the nonlinear mapping problem, and the quality of the product is predicted based on the on-line monitoring state parameters. Combined with experience of experts in the field and the production of large amounts of data knowledge mining association rules from database and matching products quality prediction results and adjusting control parameters, obtained the lime rotary kiln control parameter correction information, lime rotary kiln control system for product quality of real time pre measurement and accurate feedback adjustment of intelligent control.

\section{Model and Key Technology of Product Quality Control of Lime Rotary Kiln}

The product quality control model flow chart of lime rotary kiln is shown in figure 1 . The data preprocessing module receives data from the automatic control system of the lime rotary kiln and the data stored in the database. And then the product quality prediction model is activated according to the preset time interval. Forecast to the product quality and the quality of the pre - set quality information. To maintain the original control parameter information and you meet the requirements. If not up to meet the requirements, combined with the control parameters and product quality information, through association rules base matching control to adjust the parameters of, and feedback to the automatic control system of lime rotary kiln.

The activity of the product can be reduced by the lime burning or over burning, but the burning and burning of the lime is completely different from the operation, so it is necessary to distinguish the state of the lime. Secondly, the different chemical composition of raw material production of lime activity difference is very big, the different raw material must have the corresponding product quality 
requirements. Therefore, in order to make a correct judgment, the quality of the product must be compared with the corresponding product quality setting.

BP neural network is composed of input layer $(\mathrm{X})$, hidden layer $(\mathrm{H})$ and output layer $(\mathrm{Z})$. The hidden layer $(\mathrm{H})$ can be one or more layers, and the article chooses only one layer of hidden layer of neural network [2]. For the three layer BP neural network, the hidden layer node number can be determined by using the following formula.

$$
\mathrm{p}=\sqrt{\mathrm{m} \times \mathrm{n}}
$$

Where: $\mathrm{m}$ is the input layer node number, $\mathrm{n}$ is the output layer node number, $\mathrm{P}$ is the hidden layer node number.

BP neural network is a kind of iterative algorithm for the forward propagation of data and the error back propagation. The input signal propagates through the activation function to the hidden layer, and the hidden layer nodes are transmitted to the output layer by the activation function. By calculating output between neurons and the expected output error, in accordance with the negative gradient of error modify the weight of each layer, error signal along the path to the original return, to calculate the output, as is shown by figure1, until the error achieve ideal value.

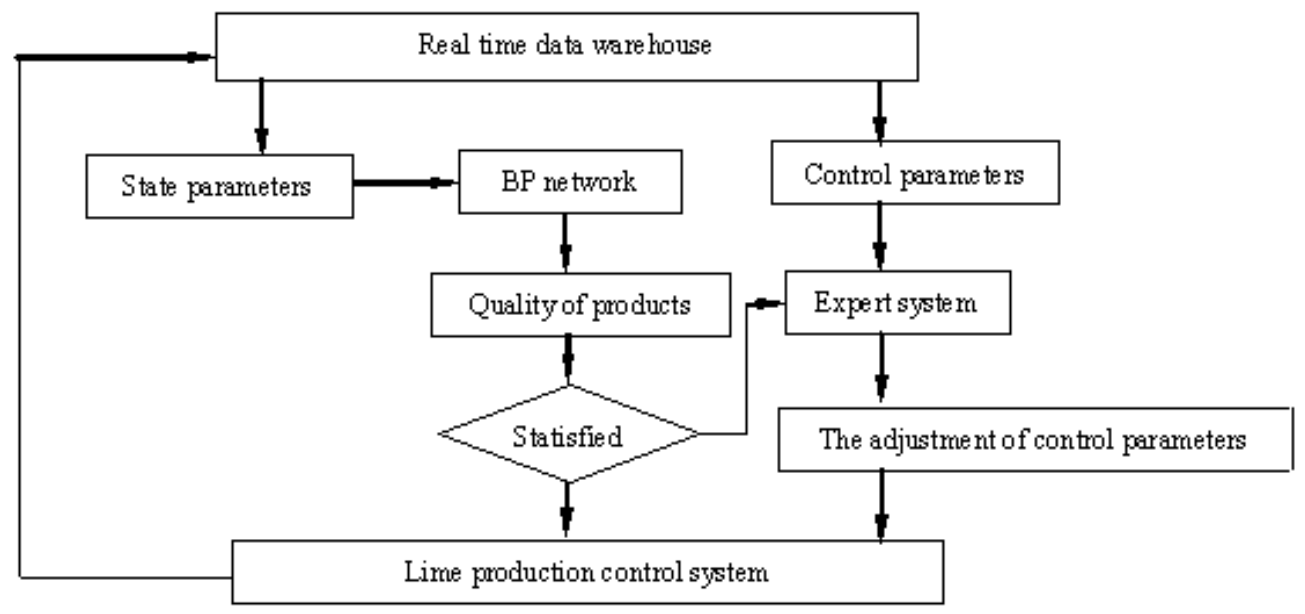

Figure 1. Flow chart of control mode

Lime rotary kiln control system online condition monitoring parameters (x) many, some reflect the process of production condition parameters of the system, some safety protection monitoring parameters, more two features in both. According to the actual production experience, exhaust gas temperature (x1), the tail of the kiln temperature (x2), kiln pressure (x3), secondary air temperature (x4), feed temperature (x5) are reflected lime quality is the most significant factor.

The control parameters $(\mathrm{Y})$ of the lime rotary kiln are essentially determined by the quality of the product. Including fuel consumption (Y1), rotary kiln rotation speed (Y2), the main exhaust fan (Y3) and other control parameters is the product quality of the decisive parameters. Product quality information (Z) contains the lime activity (z1) and the (z2) [3][4][5]. First, it is the higher the activity of lime, the better the quality of the product. In the ideal state, there is no maximum level of activity of the lime, which has the highest degree of burning or burning.

In the process of production of lime rotary kiln, there are inevitable abnormal conditions, such as mechanical equipment failure, monitoring equipment abnormal and so on will cause the distortion of online detection data. If you do not filter out the data, it will cause the system model to send out the wrong instruction, affecting the normal operation of the system. For this kind of abnormal data points to take filtering, mean filling and other means to ensure the accuracy and integrity of the data. 


\section{Construction of Expert System Rule Base}

Prediction to the quality of the product is not ideal, the need to adjust the control parameters to achieve the purpose of product quality control. Through the neural network prediction period of product quality information model is obtained, and presupposition information after comparing the parameters $\left({ }^{\Delta z_{1}^{j}}=\left|z_{1}-z_{1}^{\bar{j}}\right|, z_{2}^{\bar{j}}\right)$ and control parameters $\left(y_{1}^{\bar{j}}, y_{2}^{\bar{J}}, y_{3}^{\bar{J}}\right)$ as the association rule premise, matching the amount of correction of the control parameters as output item $\left(\Delta y_{1}^{\bar{J}}, \Delta y_{2}^{\bar{J}}, \Delta y_{3}^{\bar{J}}\right)$, then optimized control parameters in the next time interval for:

$$
y_{n}^{\bar{j}+1}=y_{n}^{\bar{j}}+\Delta y_{n}^{\bar{j}} \quad(\mathrm{n}=1,2,3)
$$

BP neural network algorithm is as follows:

(1)Initialization. In the form (2), the value of the license is randomly assigned to the initial value of the network, setting the number of learning times $\mathrm{N}$ and calculating precision.

(2)A study sample $\mathrm{K}$ input and the corresponding expected output.

(3)The output value of I node is calculated.

$$
h_{i}^{(k)}=f\left(\sum_{\mathrm{a}=1}^{\mathrm{m}} \omega_{\mathrm{ai}} x_{a}^{(k)}+\theta_{i}\right)
$$

(4) J node output value of the output layer.

$$
z \mathbf{o}_{\mathrm{j}}^{(k)}=f\left(\sum_{i=1}^{p} \omega_{\mathrm{i}} h_{i}^{(k)}+\theta_{j}\right)
$$

(5) Calculating the weights between the output layer and the hidden layer.

$$
\omega_{\mathrm{i}}^{N+1}=\omega_{i}^{N}+\left(1-b^{N+1}\right) \eta^{N+1} \delta_{\mathrm{j}}^{(k)} h_{\mathrm{i}}^{(k)}+b^{N+1} \Delta \omega_{i}^{N}
$$

Which is the learning rate, $\mathrm{B}$ is the additional momentum. The value of the judgment is determined by the formula (3) and (4) [6].

(6) Calculating the weights between the hidden layer and the input layer.

$$
\omega_{\mathrm{ai}}^{N+1}=\omega_{a i}^{N}+\left(1-b^{N+1}\right) \eta^{N+1} \delta_{\mathrm{i}}^{(k)} x_{\mathrm{a}}{ }^{(k)}+b^{N+1} \Delta \omega_{a i}^{N}
$$

(7)Judgment. Sample not read, jump second steps. Otherwise the next step.

(8)According to the corrected formula weights (5) (6), fixed weights. The output of each layer is calculated by the formula (7).

(9)To calculate the global error.

$$
E=\frac{1}{2 \mathrm{~K}} \sum_{k=1}^{\mathrm{K}} \sum_{\mathrm{j}=1}^{\mathrm{n}}\left(z_{j}{ }^{(k)}-z o_{j}{ }^{(k)}\right)^{2}
$$

(10)Judgment. Does the error reach the design accuracy or exceed the maximum number of training sessions, and then the error is. No, then make $\mathrm{N}=\mathrm{N}++$, return second steps.

The model association rule mining algorithm using OLAP and Apriori algorithm, to find the relationship between product quality information and control parameters adjustment. Product quality information and control parameters of the association rules mining, with the help of the production process by the control parameters to adjust the information on the quality of the product data.

On-line analytical processing technology is the main tool of data analysis in data warehouse. The OLAP system uses the data storage scheme of materialized data cube, in exchange for the space cost for time efficiency. For association rule mining, a large amount of intermediate data which is used in the mining process may already be materialized in the data cube and not need to be re calculated. 


\section{Running Examples of Neural Network Forecast Model}

Sample data is from a steel mill Nissan 800 tons of lime rotary kiln production line. The enterprise product quality detection is per hour from the sampling hole sampling time, artificial naked eye observation quality of products; sampling every 3 hours on the quality of the products by experimental method determination of a, so the sample selection experimental measurement data shall prevail. Select the normal operation of the equipment in the case of 30 days and 240 data for the sample, of which 120 were used as training samples, 40 as a test sample, as is shown by table1.

Table 1 Sample

\begin{tabular}{|c|c|c|c|c|c|c|c|}
\hline NO. & $\begin{array}{l}\text { The } \\
\text { temperatur } \\
\text { e of } \\
\text { exhaust } \\
\text { gas } \\
\left({ }^{\circ} \mathrm{C}\right)\end{array}$ & $\begin{array}{c}\text { The } \\
\text { temperatur } \\
\text { e of inlet } \\
\left({ }^{\circ} \mathrm{C}\right)\end{array}$ & $\begin{array}{l}\text { The } \\
\text { pressure of } \\
\text { inlet } \\
(\mathrm{Pa})\end{array}$ & $\begin{array}{l}\text { The } \\
\text { temperatur } \\
\text { e of the } \\
\text { second air } \\
\left({ }^{\circ} \mathrm{C}\right)\end{array}$ & $\begin{array}{l}\text { The } \\
\text { temperatur } \\
\text { e of } \\
\text { product } \\
\left({ }^{\circ} \mathrm{C}\right)\end{array}$ & $\begin{array}{c}\text { Activity } \\
(\mathrm{ml})\end{array}$ & $\begin{array}{l}\text { Product } \\
\text { state }\end{array}$ \\
\hline 1 & 280 & 1009 & -57.78 & 536 & 171 & 360 & $\begin{array}{c}\text { Over-burn } \\
\text { ed }\end{array}$ \\
\hline 2 & 286 & 1014 & -23.64 & 625 & 143 & 351 & $\begin{array}{c}\text { Over-burn } \\
\text { ed }\end{array}$ \\
\hline 3 & 273 & 983 & -25.54 & 630 & 95 & 335 & $\begin{array}{c}\text { under-burn } \\
\text { ed }\end{array}$ \\
\hline$\cdots$ & $\cdots$ & $\cdots$ & $\cdots$ & $\cdots$ & $\cdots$ & $\cdots$ & $\cdots$ \\
\hline 116 & 270 & 949 & -39.46 & 578 & 155 & 329 & $\begin{array}{c}\text { under-burn } \\
\text { ed }\end{array}$ \\
\hline 117 & 261 & 954 & 7.42 & 571 & 134 & 353 & $\begin{array}{c}\text { under-burn } \\
\text { ed }\end{array}$ \\
\hline 118 & 282 & 1002 & -51.04 & 630 & 127 & 365 & $\begin{array}{c}\text { Over-burn } \\
\text { ed }\end{array}$ \\
\hline 119 & 267 & 967 & -20.32 & 547 & 109 & 344 & $\begin{array}{c}\text { under-burn } \\
\text { ed }\end{array}$ \\
\hline 120 & 282 & 1006 & -55.68 & 628 & 152 & 357 & $\begin{array}{l}\text { Over-burn } \\
\text { ed }\end{array}$ \\
\hline$\cdots$ & $\cdots$ & $\cdots$ & $\cdots$ & $\cdots$ & $\cdots$ & $\cdots$ & $\cdots$ \\
\hline 159 & 286 & 996 & -12.5 & 627 & 141 & 354 & $\begin{array}{c}\text { under-burn } \\
\text { ed }\end{array}$ \\
\hline 160 & 274 & 949 & -12.01 & 597 & 112 & 341 & $\begin{array}{c}\text { under-burn } \\
\text { ed }\end{array}$ \\
\hline
\end{tabular}

Definition1: The sum rule for the attribute values of the same attribute in the $1 \mathrm{~N}$ dimensional data is as follows:

Let SUM=Attribute. Value1+Attribute.Value2

If Attribute.Value1 is not empty and Attribute.Value1==Attribute. Value2, then SUM=N+1;

If Attribute.Value1 is null and Attribute.Values2 is not empty, or Attribute.Value1 is not empty and Attribute. Value2 is empty, then SUM=1;

In other cases, $\mathrm{SUM}=0$.

The rule can be used to determine whether the 2 frequent attribute sets satisfy the connection conditions. To judge two k-item frequent attribute set Trans 1 and Trans 2 whether that satisfies the join condition, and Trans 2 Trans1 the corresponding added and all the sum of the results accumulated the resulting value to result.

Write $\mathrm{n}$ for the number of fields in the data table, if Result $=(\mathrm{n}+1)(\mathrm{k}-1)+2$, and Trans 2 Trans1 a (k-1) of non null attribute values are the same, two attribute values are different, and different two attribute values and are 1 . That was non null attribute value and attribute values are added. At this point, Trans1 and Trans 2 meet the connection conditions, can be connected operation. Otherwise, Trans 1 and Trans 2 can not be connected operation.

The 2 meet the connection conditions of frequent sets Trans1 and Trans2, can be achieved by the "add" connection operation.

In order to carry out the operation of the frequent attribute set, the "or" rule of the value of the attribute is defined first.

From the production site, the use of the quality control system before and after 1 month of the 240 measured lime activity contrast as shown in Figure 2. 


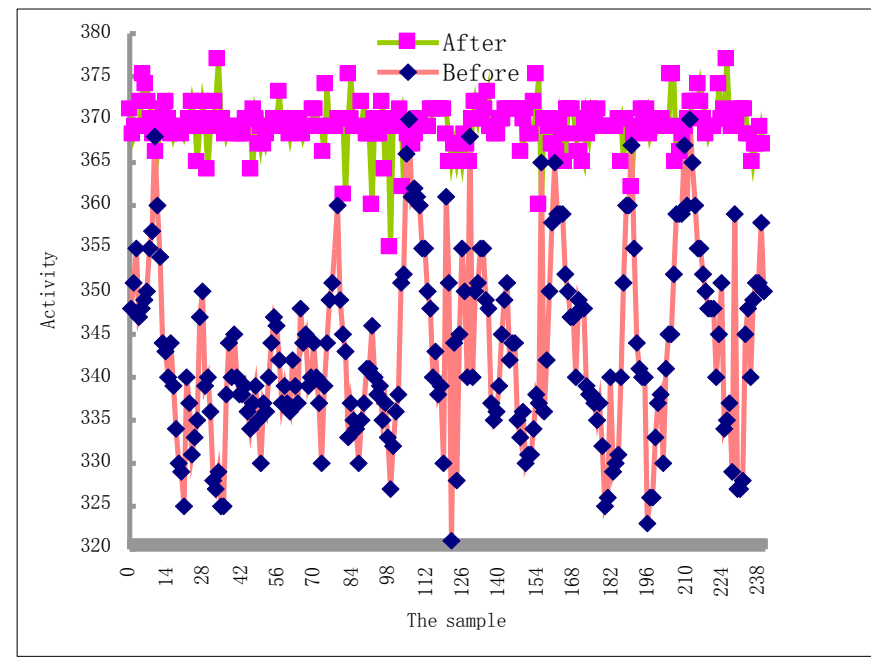

Figure 2. The contrast of product quality before and after used the system

From Figure 2 it can be seen that the use of the quality control system, the average lime activity is about $370 \mathrm{ml}$, compared with the previous product, the average $340 \mathrm{ml}$ level has greatly improved. In addition to the specific time period, the change of the activity of the lime is kept within 10ml, which indicates that the stability of the lime production system is greatly improved.

\section{Summary}

This paper presents a combination of neural network and association rule library based on lime rotary kiln products quality prediction and control parameters feedback control model can be in line completed the accurate prediction of the quality of the products and to achieve timely control parameter adjusting information feedback. In the control model, the process of reading and processing the data of the state parameter is added to improve the robustness of the control model, and reduce the influence of equipment failure on the system stability.

\section{Acknowledgements}

This paper is supported by Science and technology project of Henan Province (152102210123, 142102210475).

\section{References}

[1] Liu Xiao-li, Wang Shen-tao, Dai Rui, Wei Shi-feng, "On fault diagnosis of net work based on improved particle swarm optimization", Computer applications and software, vol.28, no.1, (2011),pp.207-209.

[2] Wang Cheng-liang,Pang Xu,Lu ZHi-jian, "Research on hybrid control methods of aluminium reduction on neural network", Application Research of Computer, vol.27,no.7, (2010),pp.2536-2539.

[3] Li Dao-zhong,ZHang Lei,Wu ZHao-hui, "Test method of physical metallurgical lime, Bei Jing:Metallurgical Industry Press,(2005),pp.1-5.

[4] Chu Hui, Lai Hui-cheng, "An improved back-propagation N algoriythm and its application", Computer simulation,vol.24, no.4, (2007), pp.75-111.

[5] Shi ZHong-zhi, "Knowledge discovery",Bei jing:Tsinghua University press, (2002),pp.8-9.

[6] Zhang Lei, Hu Chun, Qian Feng, "Research progress of BP algorithm for local minimum problem", The industrial control computer, vol.17,no.9, (2004),pp.33-50. 